\title{
Infraestrutura logística e comércio internacional: uma análise a partir do Modelo de Gravidade
}

\author{
Leonardo Dias Fernandes Simões ${ }^{1}$ \\ Carolina Rodrigues Corrêa Ferreira ${ }^{2}$ \\ Hilton Manoel Dias Ribeiro ${ }^{3}$
}

\begin{abstract}
Resumo: A infraestrutura de transportes impacta diretamente nos custos de comércio e, consequentemente, na competitividade dos países. Assim, o presente trabalho tem como objetivo identificar o impacto que fatores infraestruturais e, principalmente, de transportes geram sobre a exportação dos países, utilizando dados do ano de 2015 e uma amostra de 138 países. Para tanto, lança-se mão do modelo de gravidade. Os principais resultados confirmam que as variáveis representativas da infraestrutura logística (rodoviária, ferroviária e aeroportuária) afetam positivamente as exportações, salientando-se, assim, a importância dos países, principalmente os emergentes, investirem na melhoria dos diversos modais de transporte para ampliar sua inserção no mercado internacional.
\end{abstract}

Palavras-chave: Comércio Internacional. Infraestrutura Logística. Modelo de gravidade.

Abstract: Transport infrastructure has a direct impact on the trade's costs and country's competitiveness. Thus, the present work aims to identify the impact that infrastructural and, mainly, transport infrastructure generates on the countries' exports, using data for the year 2015 and a sample of 138 countries. Therefore, the Gravity Model is used.The main results confirm that the variables that represent the logistics infrastructure (road, rail and airport) positively affect exports, thus emphasizing the importance of countries, especially emerging ones, to invest in the improvement of the various modes of transportation to increase their insertion in the international market.

Keywords: Gravity Model. International Trade. Logistics Infrastructure.

\section{Introdução}

Considerando a ampliação na integração das economias nacionais em uma economia internacional, por meio da globalização econômica, discussões sobre melhoria dos meios de transporte e comunicação tornaram-se cada vez mais importantes para as análises de comércio internacional. Existe um esforço por parte dos países membros da Organização Mundial do Comércio (OMC) para reduzir obstáculos nas transações de bens e serviços e, nos últimos anos, os países vêm reduzindo barreiras a esse comércio.

\footnotetext{
${ }^{1}$ Graduado em Ciências Econômicas pela Universidade Federal de Juiz de Fora - Campus GV (UFJF/ GV). Colaborador no Econúcleo (UFJF/GV). E-mail: leo_skz@hotmail.com.

${ }^{2}$ Graduada em Ciências Econômicas pela Universidade Federal de Viçosa (UFV). Doutora em Economia Aplicada (UFV). Profa.. Adjunta no Dep. de Economia (UFJF-GV) e Pesquisadora no Econúcleo (UFJF/GV). E-mail: carolina.correa@ufjf.edu.br.

3 Graduado em Ciências Econômicas (UFV). Doutor em Economia (UFJF). Prof. Adjunto no Dep. de Economia (UFJF/GV) e Pesquisador no Econúcleo (UFJF/GV). E-mail: hilton.manoel@ufff.edu.br.
}

Página 187 Caderno de Ciências Sociais Aplicadas, Vitória da Conquista/BA, vol. 16, n 27, ano 16, p. 187-204, jan/jun 2019. 
A OMC (2015) entende como facilitação do comércio aquelas ações que aumentam a eficiência dos processos de troca e, consequentemente, envolvem o entendimento sobre a eficiência nos setores de transportes, segurança, aduaneiros, harmonização de práticas e regras comerciais. Segundo Duval (2007), a facilitação de comércio depende da melhora conjunta desses e outros fatores que levam a transações comerciais mais eficientes.

Nessa linha, Portugal-Peréz e Wilson (2012) apontam que a facilitação do comércio pode ser feita de duas maneiras, uma que engloba processos tangíveis e mais complexos, tais como infraestrutura de portos, estradas, ferrovias e telecomunicação; e uma segunda que engloba processos intangíveis e mais simples, relacionados à transparência, gestão alfandegária eficiente, ambiente de negócios e aspectos institucionais. Zaki (2014) aponta como variáveis para facilitação de comércio a simplificação dos procedimentos comerciais e documentação, harmonização das práticas e regras comerciais, informação e procedimentos mais transparentes, uso de novas tecnologias e meios de pagamentos mais seguros. Korinek e Sourdin (2011), por seu turno, apontam que a desburocratização dos procedimentos aduaneiros e de administração de fronteiras e a agilização desses procedimentos são fundamentais para aumentar a competitividade de um país.

Dentre os fatores facilitadores de comércio supracitados, a eficiência do setor de transportes recebe destaque por conta do aumento comercial dos países, dada a necessidade dos bens e serviços estarem ao alcance dos compradores em intervalos de tempo cada vez menores. Além disso, os custos com transporte representam grande parte do custo final dos produtos (CHINELATO et al., 2011). Sendo assim, melhorias e investimentos em infraestrutura de transportes podem reduzir o preço final dos bens e serviços, aumentando assim a competitividade dos países no mercado externo.

Assim, o objetivo geral desse artigo é avaliar os impactos das condições de infraestrutura dos países, enquanto facilitadoras de comércio, sobre suas exportações, no ano de 2015. Especificamente, propõe-se uma comparação entre indicadores de infraestrutura do Brasil e dos demais países, bem como verificar o impacto de indicadores de infraestrutura sobre o comércio internacional de bens manufaturados, por meio da aplicação do Modelo de Gravidade.

Espera-se que países com maior eficiência na infraestrutura de transportes sejam mais competitivos no mercado externo. Apesar dos trabalhos já existentes na literatura, são poucos os que buscam quantificar o impacto sobre o comércio. Portanto, o presente trabalho agrega à discussão já existente, produzindo informações que possam orientar a criação de políticas públicas para promoção de investimentos em infraestrutura logística, reduzindo barreiras ao comércio.

Página 188 Caderno de Ciências Sociais Aplicadas, Vitória da Conquista/BA, vol. 16, n 27, ano 16, p. 187-204, jan/jun 2019. 
Além dessas considerações iniciais, este trabalho contempla uma discussão teórica sobre infraestrutura, comércio e evidência empíricas na seção 1; apresenta a metodologia e base de dados na seção 2; discute os resultados na seção 3; seguido das considerações finais.

\section{Infraestrutura e comércio}

O histórico de economias bem-sucedidas mostra que os investimentos em infraestrutura têm fundamental importância na modernização do país, devendo se situar em níveis elevados por muitos anos, o que não foi o caso do Brasil (FRISCHTAK, 2008). A Tabela 1 indica a realização de investimentos em infraestrutura no Brasil desde a década de 1970, chegando a uma média de 5,42\% do Produto Interno Bruto (PIB) nesta primeira década. Desse total, 2,03\% eram investimentos focados no setor de transportes, reforçando o peso expressivo do setor sobre o processo de industrialização e crescimento da economia brasileira neste período.

Tabela 1: Média dos investimentos em infraestrutura no Brasil (\% do PIB)

\begin{tabular}{lcccc}
\hline Período & $1971-1980$ & $1981-1990$ & $1991-2000$ & $2001-2010$ \\
\hline Total (\% PIB) & 5,42 & 3,62 & 2,29 & 2,19 \\
Eletricidade & 2,13 & 1,47 & 0,76 & 0,67 \\
Telecomunicações & 0,8 & 0,43 & 0,73 & 0,64 \\
Transportes & 2,03 & 1,48 & 0,63 & 0,64 \\
Água e saneamento & 0,56 & 0,24 & 0,15 & 0,19 \\
\hline
\end{tabular}

Fonte: Frischtak (2013).

Na década de 1980 houve uma crise financeira e fiscal no Brasil que dificultou a captação de crédito no exterior, além de algumas mudanças institucionais (Constituição de 1988) que levaram a contrações nos investimentos em infraestrutura, para equilibrar as contas públicas (FRISCHTAK, 2013). Observa-se que a média de investimentos em infraestrutura, de 2001 a 2010, foi de 2,19\% do PIB, abaixo do necessário para sustentar o crescimento econômico que, segundo Estache (2012), seria de 4\% a 6\% para países da América Latina. Considerando anos mais recentes da Tabela 1 (2001-2010), apesar da instalação do Programa de Aceleração do Crescimento (PAC), o máximo de investimento em infraestrutura alcançado foi de 2,49\% do PIB, em 2009, sendo que no setor de transporte esse valor foi de 0,64 (média da década).

A provisão de infraestrutura em transportes é capaz de viabilizar elevadas economias de escala, alterando o padrão de comércio e gerando vantagens comparativas estáticas (LIMA et al.,1997). Ainda, segundo os autores, no caso do Brasil há momentos históricos em que a implementação de um novo corredor de transporte facilitou a exploração de um determinado recurso natural existente, causando

Página 189 Caderno de Ciências Sociais Aplicadas, Vitória da Conquista/BA, vol. 16, n 27, ano 16, p. 187-204, jan/jun 2019. 
uma alteração permanente da estrutura de exportações brasileiras. Tem-se como exemplo a construção das estradas de ferro Vitória-Minas e Carajás, durante o ciclo do minério de ferro, que continuam, ainda hoje, sendo as maiores ferrovias em carga transportada do país; ou a extensa malha rodoviária construída no período de 1960-1980 para escoação de produtos agrícolas exportados pelo Brasil. No país, o transporte rodoviário é o principal meio de escoamento da mercadoria, representando 61,1\% do total de transporte de cargas, seguido pelo ferroviário (20,7\%) e Aquaviário (13,6\%) (CONFEDERAÇÃO NACIONAL DO TRANSPORTE - CNT, 2016).

Apesar do peso das rodovias no setor de transportes brasileiro, segundo a CNT (2016), apenas 12,2\% das rodovias são pavimentadas. Além da má condição das estradas, a malha rodoviária existente no Brasil é muito inferior, se comparada a de países como China e Estados Unidos, por exemplo. A malha rodoviária do Brasil é de $25 \mathrm{~km}$ por $1000 \mathrm{~m}^{2}$, contra 438,1 $\mathrm{km}$ dos Estados Unidos e 359,9 km da China. Além disso, o custo com acidentes rodoviários em 2015 foi de R \$ 11,15 bilhões, quase o dobro do investimento público federal em rodovias em 2015, que foi de $\mathrm{R} \$ 5,95$ bilhões.

A grande utilização das rodovias evidencia a precariedade das outras modalidades de transporte, como os aquaviários e ferroviários, que poderiam ser utilizados como alternativas para aliviar o grande fluxo de caminhões nas rodovias brasileiras. Além do pouco investimento na infraestrutura de transportes, o Brasil ainda enfrenta uma série de deficiências para colocar projetos em prática, citando as ferrovias Transnordestina e Norte-Sul, as quais encontram-se inacabadas e sem previsão para conclusão das obras (MACHADO, 2016).

No que tange a relação direta entre infraestrutura e desempenho do comércio, alguns estudos corroboram essa associação (KORINEK \& SOURDINI, 2011; SOUZA \& BURNQUIST, 2011; PAULA \& SILVA, 2015). Os primeiros mostram como serviços logísticos de qualidade são importantes facilitadores de comércio, economizando tempo e dinheiro nas transações. Os autores avaliaram o impacto da infraestrutura logística para 234 países, no ano de 2008, mostrando como o papel das infraestruturas aérea e marítima aumenta o volume de comércio, considerando países de baixa, média e alta renda. Os resultados indicaram que o comércio se beneficia relativamente mais de uma melhora na infraestura aérea, uma vez que os produtos transportados por este modal geralmente são mais perecíveis e que requerem uma maior qualidade logística de trasnporte. Os resultados também mostraram que o aumento na qualidade de infraestrutura, de forma geral, leva a diferentes resultados para cada tipo de economia, sendo as economias de renda média as mais beneficiadas pelo aumento dos investimentos em infraestrutura, uma vez que as economias de baixa renda não conseguem absorver

Página 190 Caderno de Ciências Sociais Aplicadas, Vitória da Conquista/BA, vol. 16, n 27, ano 16, p. 187-204, jan/jun 2019. 
esses ganhos e as economicas de alta renda já passaram da etapa de ganhos marginais crescentes a partir dos investimentos em infraestrutura.

Souza e Burnquist (2011) estimaram e avaliaram os efeitos de variáveis como a tecnologia de informação, número de documentos exigidos para comercializar e tempo de desembaraço alfandegario, sobre o comércio internacional. Os autores concluiram que a primeira variável é um fator importante para a facilitação do comércio e que os resultados obtidos para as demais variáveis mostram como o Brasil está relativamente deficiente nesse aspecto, revelando que uma melhora nesses fatores aumentaria o comércio, via mais eficiência e menos burocracia, por exemplo.

Já Paula e Silva (2015) analisaram indicadores de competitividade como o desempenho econômico, eficiência dos governos, eficiência dos negócios e infraestrutura, para o período de 1997 a 2011. Os autores encontraram uma relação positiva entre a competitividade no comércio internacional e todas essas variáveis, mostrando a importância de se melhorar o ambiente de negócios, reduzir os entraves e ampliar investimentos em tecnologia e infraestrutura.

Especificamente sobre estudos empíricos baseados nos dados para o Brasil, alguns autores podem ser considerados (WANKE \& HIJAR, 2009; CHINELATO et al., 2011). Os primeiros avaliaram as deficiências do transporte no país por intermédio da aplicação de questionários realizados com vários exportadores brasileiros. Segundo os autores, algumas das principais dificuldades encontradas pelos exportadores referem-se à dificuldade de escoamento e acesso aos portos; falta de disponibilidade de armazenamento; pouca infraestrutura rodoviária e hidroviária; dificuldade de movimentação de carga; demora na liberação de mercadorias e greves; e dificuldade de disponibilidade do transporte aéreo, devido à baixa frequência de aviões e disponibilidade de rotas internacionais.

Já Chinelato et al. (2011) tentaram mostrar como a logística de transportes do país afeta o custo final da mercadoria. Foi analisado o custo do transporte de uma carga da cidade de São Paulo para a Áustria, via transporte marítimo e aéreo. Os autores identificaram que o transporte terrestre até o porto foi mais caro que o frete marítimo do porto de Santos até a Àustria, e que o valor total do frete marítimo representou $9,49 \%$ do valor da carga, enquanto o frete aéreo representaria $5,82 \%$. O trabalho apresenta certas limitações referentes à amostra descrita.

Página 191 Caderno de Ciências Sociais Aplicadas, Vitória da Conquista/BA, vol. 16, n 27, ano 16, p. 187-204, jan/jun 2019. 


\section{Modelo de Gravidade e evidências empíricas}

Diversos são os fatores que impactam os fluxos de comércio entre os países, tais como os custos de transporte, tarifas e barreiras não tarifárias. Outros fatores como o crescimento dos países (mensurado pelo PIB) e a distância geográfica entre eles, vêm ganhando grande importância com o uso de modelos gravitacionais, baseados na teoria da gravidade de Newton (SHEPHERD, 2013).

De acordo com Baldwin e Taglioli (2006), o modelo gravitacional é uma ferramenta amplamente utilizada em vários campos empíricos e tem uma série de aplicações no estudo do comércio internacional. Sua popularidade baseia-se em três pilares: primeiro, os fluxos comerciais internacionais são um elemento-chave em todos os tipos de relações econômicas; segundo, os dados necessários para estimá-los são de fácil acesso; terceiro, um grande número de trabalhos de alto padrão trouxe maior respeitabilidade ao modelo de gravidade.

Levando essa teoria para o campo econômico, é possível analisar o fluxo de comércio internacional ou inter-regional. Pode-se dizer que os fluxos comerciais bilaterais têm relação direta com o tamanho da economia (medida pelo PIB) e uma relação inversa com a distância geográfica entre eles. A equação que mostra essa ideia pode ser representada conforme (1):

$\mathrm{X}_{\mathrm{ij}}=\alpha \frac{\mathrm{Y}_{\mathrm{i}} \mathrm{Y}_{\mathrm{i}}}{\mathrm{D}_{\mathrm{ij}}}$

em (1), o termo $X_{i j}$ representa o fluxo comercial com origem no país i e destino no país j; $\alpha$ é uma constante de proporcionalidade; os termos $Y_{i}$ e $Y_{j}$ representam o PIB de cada país ou região representada, que serve como proxy para o tamanho da economia; e o $D_{i j}$ representa a distância geográfica entre eles, que é utilizada como proxy para os custos de transporte. Linearizando, temos a equação básica do modelo de gravidade, conforme (2):

$\operatorname{LnX}_{\mathrm{ij}}=\operatorname{Ln} \alpha+\operatorname{LnY}_{\mathrm{i}}+\operatorname{Ln} \mathrm{Y}_{\mathrm{j}}-\operatorname{LnD}_{\mathrm{ij}}$

Tinbergen (1962) e Pöyhönen (1963) utilizaram este modelo para explicar o fluxo de comércio bilateral. Os autores argumentam que o tamanho da economia do país está associado ao desempenho do comércio e seu fluxo é inversamente proporcional às suas distâncias, medido pela distância geográfica entre suas regiões.

Página 192 Caderno de Ciências Sociais Aplicadas, Vitória da Conquista/BA, vol. 16, n 27, ano 16, p. 187-204, jan/jun 2019. 
Anderson (1979) apresentou microfundamentos para o modelo de gravidade. O autor introduziu uma explicação teórica para seu modelo que tinha como objetivo analisar o comércio de commodities. Segundo o autor, a relevância do modelo ocorre por possibilitar medir diversas quantidades e tipos de bens que podem ser comercializados entre fronteiras.

Anderson e Van Wincoop (2003; 2004) fizeram uma extensão do modelo básico, empregando outros tipos de barreiras para o comércio, além da distância geográfica. Isso fez com que o modelo atingisse a abordagem teórica de hoje, sendo largamente utilizado para estudos econômicos na área do comércio internacional. Visto que outros fatores, além da distância geográfica entre os países, afetam negativamente o comércio entre regiões, foi possível empregar outras variáveis que possivelmente seriam barreiras ao comércio e tentar identificar seus efeitos sobre o mesmo. Desde então, o modelo é utilizado com outras variáveis, como tarifas comerciais, barreiras técnicas e sanitárias, semelhança cultural entre os países, idioma, participação em blocos comerciais afins, entre outras. A equação que demonstra os efeitos das barreiras ao comércio pode ser expressa conforme (3):

$\operatorname{LnX}_{\mathrm{ij}}=\alpha+\beta_{1} \operatorname{LnY}_{\mathrm{i}}+\beta_{2} \operatorname{Ln} \mathrm{Y}_{\mathrm{j}}+\beta_{3} \operatorname{LnD}_{\mathrm{ij}}+\sum_{\mathrm{m}=1}^{\mathrm{M}} \delta_{\mathrm{m}} \operatorname{LnB}_{\mathrm{mij}}+\mu_{\mathrm{ij}}$

em que $\alpha$ é o termo de intercepto; $\beta^{\prime}$ s são os coeficientes de inclinação; $X_{i j}$ representa o fluxo de comércio do país i para o país j; $Y_{i}$ e $Y_{j}$ representam o PIB dos países i e j respectivamente; $D_{i j}$ é a distância geográfica entre os países i e j; $B_{m i j j}$ representa um vetor de variáveis selecionadas como proxies para barreiras comerciais; e $\mu_{i j}$ é o valor residual.

$\mathrm{Na}$ aplicação deste modelo, Corrêa et al., (2015) verificaram se as medidas técnicas e sanitárias aplicadas à importação de bens pelo Brasil estão servindo o propósito de proteger os consumidores e melhorar a qualidade dos produtos importados, ou se estão servindo como barreiras não tarifárias aplicadas ao comércio internacional. Foram analisados os números de notificações emitidas pelo Brasil entre os anos de 2000 a 2012, tomando como base os principais produtos importados pelo Brasil, e seus maiores parceiros comerciais. Os resultados mostraram que as medidas técnicas adotadas pelo Brasil não caracterizam barreiras não tarifárias, o que quer dizer que o país está cumprindo os objetivos do acordo TBT (barreiras técnicas do comércio). Sendo assim, as TBTs aplicadas pelo Brasil aumentam o comércio, e isso pode ser explicado pela padronização e segurança dos produtos importados, que essas exigências trazem.

Página 193 Caderno de Ciências Sociais Aplicadas, Vitória da Conquista/BA, vol. 16, n 27, ano 16, p. 187-204, jan/jun 2019. 
Almeida et al. (2011) buscaram verificar a influência dos custos de transporte para o café brasileiro entre os anos de 2000 a 2006. Os resultados mostraram que a distância entre as capitais dos países analisados afeta negativamente o comércio, como esperado, sendo que um aumento de 10\% na distância entre as capitais aumenta os custos de transporte em 4\%, em média. Outra variável como "comércio com países que fazem fronteira com o Brasil" não apresentou coeficiente significativo. Segundo os autores, esse resultado pode ter sido encontrado devido à grande extensão territorial brasileira e pelo fato de que a maior parte do transporte ser feita por terra, elevando os custos, devido à longa distância e às condições da infraestrutura rodoviária.

Paula et al., (2012) analisaram como certos fatores de competitividade afetam o comércio. Variáveis como índice de desempenho econômico, eficiência do governo, eficiência dos negócios e infraestrutura, para 57 países, entre os anos de 1997 e 2010, foram incorporadas ao modelo. Os resultados mostraram que melhorias em cada um desses índices afetam positivamente o comércio, destacando-se o índice de eficiência nos negócios. Este resultado revela que fatores como produtividade e eficiência, práticas de gestão e aspectos do mercado de trabalho são importantes para aumentar a competitividade e, consequentemente, o comércio internacional. $O$ resultado também mostrou a importância da melhoria da infraestrutura, concluindo que investimentos nesta área são fundamentais para os países conseguirem aproveitar novas oportunidades de comércio. Por fim, outra variável relevante foi uma dummy para regiões que identificou uma tendência de redução comercial entre países com o mesmo nível econômico.

\section{Modelo Empírico}

Para mensurar o impacto da infraestrutura geral e, especialmente, da infraestrutura logística sobre o comércio internacional, estima-se uma equação baseada no modelo de gravidade, para o ano de 2015. O uso de dados em cross-section possui limitações, entre elas, a perda do componente histórico. Sendo assim, não é objetivo deste trabalho analisar as mudanças ao longo do tempo. A análise está focada unicamente em mostrar os efeitos da infraestrutura logística sobre as exportações dos países em ano mais recente.

A estimação foi feita pelo método Poisson Pseudo Maximum Likelihood (PPML), por meio do software Stata 12. De acordo com Silva e Tenreyro (2006), este método é preferível ao método de Mínimos Quadrados Ordinários (MQO), pois gera resultados consistentes na presença de heterocedasticidade não observável. Além disso, esse método é mais adequado à variável dependente

Página 194 Caderno de Ciências Sociais Aplicadas, Vitória da Conquista/BA, vol. 16, n 27, ano 16, p. 187-204, jan/jun 2019. 
em questão, as exportações, uma vez que esta apresenta muitos valores iguais a zero e este modelo por ser um modelo não linear - possibilita a inclusão de comércio zero, evitando o viés de seleção amostral. Assim, a função a ser estimada assume a forma (4):

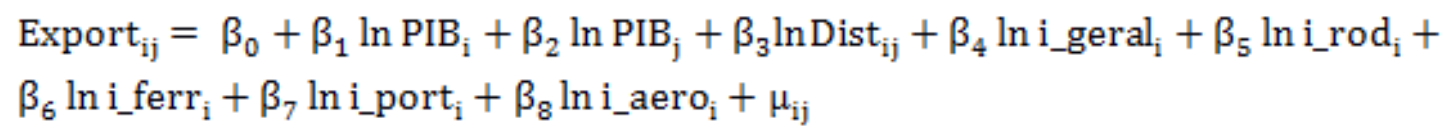

em que Export $t_{i j}$ são as exportações do país i para o país j; $P I B_{i}$ e $P I B_{j}$ são os PIBs do país exportador i e do país importador j, respectivamente; Dist $_{i j}$ é a distância geográfica entre o país i e o país j; $i \_$geral $_{i}$ é o índice da qualidade de infraestrutura geral do país i; $i$ rod ro $_{i}$ é índice da qualidade da infraestrutura rodoviária do país i; $i_{-}$ferr $_{i}$ é o índice da qualidade da infraestrutura ferroviária do país i; $i \_$port $_{\bar{i}}$ é o índice da qualidade da infraestrutura portuária do país i; $i$ aero é o índice da qualidade da infraestrutura aeroportuária do país i; e $\mu_{i j}$ é o termo de erro.

\section{Base de dados}

Os dados utilizados referem-se ao ano de 2015, para uma amostra de 138 países ${ }^{4}$. A decisão da utilização desse ano baseou-se no fato de ser, no momento da realização deste trabalho, o ano que apresentava maior disponibilidade de dados para as variáveis analisadas.

Os dados de exportação de produtos manufaturados foram retirados da plataforma de dados WITS (World Integrated Trade Solution). Os produtos manufaturados representam a maior parte das exportações do mundo, representando $70 \%$ do valor total dos produtos exportados no mundo em 2015 (OMC, 2016). Já os valores do PIB foram coletados no site do Banco Mundial e a distância geográfica entre os países foi retirada da base de dados do CEPII (Centre d'Études Prospectives et d'Informations Internationales). Os índices de infraestrutura utilizados para análise foram retirados do relatório de Competitividade Global de 2016, realizado pelo Fórum Econômico Mundial.

Os índices de infraestrutura logística são obtidos por meio de pesquisas de opinião realizadas entre executivos de cada país. Os entrevistados avaliam a qualidade de cada modelo de transporte, ofertando nota de 1 a 7 (1 para extremamente subdesenvolvido e 7 para extremamente desenvolvido), avaliando suas condições de uso, extensão e eficiência. Já o índice de infraestrutura geral é uma média

${ }^{4}$ A lista de países que compõe a amostra analisada encontra-se no Anexo 1.

Página 195 Caderno de Ciências Sociais Aplicadas, Vitória da Conquista/BA, vol. 16, n 27, ano 16, p. 187-204, jan/jun 2019. 
ponderada das infraestruturas logísticas, junto com mais outros índices, como de acesso à água, eletricidade e rede móvel de telefonia. A Tabela 2 apresenta um sumário das variáveis selecionadas.

Tabela 2: Variáveis e suas respectivas fontes e escalas de medidas

\begin{tabular}{|c|c|c|c|}
\hline Variável & Unidade & Fonte & $\begin{array}{c}\text { Sinal } \\
\text { esperado }\end{array}$ \\
\hline Exportações & Em milhares de dólares (US\$) & WITS & \\
\hline Produto Interno Bruto & Em dólares (US\$) & Banco Mundial & + \\
\hline Distância geográfica & Em Quilômetros, entre as cidades mais populosas de cada país & CEPII & - \\
\hline $\begin{array}{l}\text { Qualidade da infraestrutura } \\
\text { geral }\end{array}$ & $\begin{array}{l}\text { Média dos índices de infraestrutura logística, acesso à água, } \\
\text { telefonia e rede móvel de telefonia; 1=extremamente } \\
\text { subdesenvolvida (entre os piores do mundo); } 7=\text { extremamente } \\
\text { desenvolvido (entre os melhores do mundo) }\end{array}$ & $\begin{array}{c}\text { Fórum Econômico } \\
\text { Mundial }\end{array}$ & + \\
\hline $\begin{array}{l}\text { Qualidade da infraestrutura } \\
\text { rodoviária }\end{array}$ & $\begin{array}{l}\text { No seu país, como é a qualidade (em extensão e condições de } \\
\text { uso) do transporte rodoviário? 1=extremamente } \\
\text { subdesenvolvido (entre os piores do mundo); } 7=\text { extremamente } \\
\text { desenvolvido (entre os melhores do mundo) }\end{array}$ & $\begin{array}{c}\text { Fórum Econômico } \\
\text { Mundial }\end{array}$ & + \\
\hline $\begin{array}{l}\text { Qualidade da infraestrutura } \\
\text { ferroviária }\end{array}$ & $\begin{array}{l}\text { No seu país, como é a qualidade (em extensão e condições de } \\
\text { uso) do transporte ferroviário? } \\
1=\text { extremamente subdesenvolvido (entre os piores do mundo); } \\
7=\text { extremamente desenvolvido (entre os melhores do mundo) }\end{array}$ & $\begin{array}{c}\text { Fórum Econômico } \\
\text { Mundial }\end{array}$ & + \\
\hline $\begin{array}{l}\text { Qualidade da infraestrutura } \\
\text { portuária }\end{array}$ & $\begin{array}{l}\text { No seu país, como é a qualidade (em extensão e condições de } \\
\text { uso) do transporte portuário? } \\
\text { *Para países sem costa marítima é perguntado sobre a facilidade } \\
\text { de acesso aos portos } \\
1=\text { extremamente subdesenvolvido (entre os piores do mundo); } \\
7=\text { extremamente desenvolvido (entre os melhores do mundo) }\end{array}$ & $\begin{array}{c}\text { Fórum Econômico } \\
\text { Mundial }\end{array}$ & + \\
\hline $\begin{array}{l}\text { Qualidade da infraestrutura } \\
\text { aeroportuária }\end{array}$ & $\begin{array}{l}\text { No seu país, como é a qualidade (em extensão e condições de } \\
\text { uso) do transporte aeroviário? } \\
1=\text { extremamente subdesenvolvido (entre os piores do mundo); } \\
7=\text { extremamente desenvolvido (entre os melhores do mundo) }\end{array}$ & $\begin{array}{c}\text { Fórum Econômico } \\
\text { Mundial }\end{array}$ & + \\
\hline
\end{tabular}
Fonte: Elaboração própria.

A primeira análise descritiva dos dados é feita para o grupo de países emergentes (Tabela 3). A classificação entre países desenvolvidos e emergentes segue indicação do Fundo Monetário Internacional - FMI (2017). A metodologia do FMI engloba, entre outras variáveis: i) o nível de renda per capita; ii) o acesso ao mercado externo; e iii) e a vulnerabilidade financeira dos países (NIELSEN, 2011).

Tabela 3: Nível de Infraestrutura dos países emergentes - 2015

\begin{tabular}{lccc}
\hline Infraestrutura & Média & Mínimo & Máximo \\
\hline Geral & 3,76 & 2,36 & 6,43 \\
Rodoviária & 3,70 & 2,19 & 6,61 \\
Ferroviária & 2,73 & 1,29 & 5,12 \\
Portuária & 3,67 & 1,37 & 6,47 \\
Aeroportuária & 4,01 & 1,50 & 6,72 \\
\hline
\end{tabular}

Fonte: Elaboração própria a partir de Global Competitiveness Report (2015.) 
Vale destacar que o Brasil se encontra abaixo da média em todas as modalidades, chegando perto do mínimo algumas vezes. Colocando o país no ranking com países emergentes (103 países no total), o Brasil se encontra nas seguintes colocações: infraestrutura Geral, $88^{\circ}(2,87)$; rodoviária, $86^{\circ}$ (2,75); ferroviária, $67^{\circ}(1,75)$; portuária, $84^{\circ}(2,71)$; e aeroportuária, $61^{\circ}(3,79)$.

Já a Tabela 4 revela a média dos índices de infraestrutura dos países considerados avançados, assim como seus valores mínimos e máximos. Esse grupo é composto por 34 países. O Brasil se encontra abaixo de todos os países deste grupo, estando apenas à frente da Eslováquia, no índice de infraestrutura aeroportuária.

Tabela 4: Nível de Infraestrutura geral dos países avançados - 2015

\begin{tabular}{lccc}
\hline Infraestrutura & Média & Mínimo & Máximo \\
\hline Geral & 5,36 & 4,11 & 6,47 \\
Rodoviária & 5,17 & 3,31 & 6,22 \\
Ferroviária & 4,81 & 2,83 & 6,69 \\
Portuária & 5,20 & 3,16 & 6,77 \\
Aeroportuária & 5,50 & 3,52 & 6,80 \\
\hline
\end{tabular}

Fonte: Elaboração própria a partir de Global Competitiveness Report (2015).

A partir dessa configuração dos dados, o próximo passo contempla uma análise mais complexa da relação entre esse conjunto de indicadores de infraestrutura e o nível de atividade comercial, representada pelas exportações de produtos manufaturados. O próximo capítulo traz os resultados da aplicação do modelo de gravidade.

\section{Resultados e discussões}

Sobre os resultados do método PPML, expostos na Tabela 5, reforça-se a vantagem deste tipo de aplicação que possibilita a inclusão de fluxo de comércio com valores iguais à zero na amostra. Cabe destacar que grande parte dos valores das exportações bilaterais foram iguais à zero (aproximadamente $35 \%$ ). Nota-se que todos os coeficientes se mostraram estatisticamente significativos, exceto o de infraestrutura portuária. Os coeficientes estimados para as variáveis PIB do país importador e PIB do país exportador apresentaram sinais positivos, de acordo com o esperado, e foram estatisticamente significativos ao nível de $1 \%$. Isso sugere que um aumento no PIB do país exportador pode aumentar as exportações de bens manufaturados; já o aumento no PIB do país importador pode levar a um aumento nas exportações destes bens. O coeficiente estimado para a variável distância geográfica

Página 197 Caderno de Ciências Sociais Aplicadas, Vitória da Conquista/BA, vol. 16, n 27, ano 16, p. 187-204, jan/jun 2019. 


\section{- Cadernos de Ciénclas SOCIAIS APLICADAS}

também foi estatisticamente significativo, apresentando sinal negativo, sugerindo que o aumento da distância geográfica entre os países pode reduzir as exportações.

O coeficiente estimado para a variável de infraestrutura rodoviária mostrou-se estatisticamente significativo e com sinal positivo, conforme o esperado. Sugere-se que a melhora neste indicador tende a aumentar as exportações de bens manufaturados. A variável de infraestrutura ferroviária também apresentou coeficiente com sinal positivo, sugerindo que o aumento no índice pode levar a um aumento nas exportações de bens manufaturados dos países. Por fim, o coeficiente para infraestrutura aeroportuária indica que a melhora neste índice pode causar um aumento sobre as exportações de bens manufaturados.

Tabela 5: Resultados da estimação do modelo de gravidade

\begin{tabular}{lc}
\hline Variáveis & Coeficientes \\
\hline Produto Interno Bruto (país importador i) & $0,7676^{* * *}$ \\
Produto Interno Bruto (país exportador j) & $(0,0432)$ \\
& $0,8055^{* * *}$ \\
Distância geográfica (ij) & $(0,0355)$ \\
& $-0,7296^{* * *}$ \\
Qualidade da infraestrutura geral & $(0,0436)$ \\
& $-4,4569^{* * *}$ \\
Qualidade da infraestrutura rodoviária & $(0,8945)$ \\
& $2,0228^{* * *}$ \\
Qualidade da infraestrutura ferroviária & $(0,3854)$ \\
& $1,9614^{* * *}$ \\
Qualidade da infraestrutura portuária & $(0,5904)$ \\
& $-0,4989$ \\
Qualidade da infraestrutura aeroportuária & $(0,3130)$ \\
& $1,1765^{* *}$ \\
Constante & $(0,4615)$ \\
\hline Observações & $-22,5778^{* * *}$ \\
$\mathrm{R}^{2}$ & $(1,6218)$ \\
\hline
\end{tabular}

Nota: $* * *, * *, *$ denotam os níveis de significância a $1 \%, 5 \%$ e $10 \%$ respectivamente. Desvio-padrão entre parênteses. Sofware Stata 12.

Fonte: Elaboração própria a partir dos resultados da pesquisa. 
Especificamente sobre a variável que mede qualidade da infraestrutura portuária, apesar da literatura empírica (KORINEK \& SOURDINI, 2011) sugerir uma relação positiva entre esta e o desempenho do comércio internacional, o resultado mostrou-se não significativo e com sinal de coeficiente não esperado. Salienta-se que esta variável mede a qualidade dos portos, podendo não representar uma proxy adequada.

Estes resultados ressaltam a importância que a infraestrutura logística possui sobre o comércio internacional, aumentando o fluxo de bens entre os países e regiões. Segundo IPEA (2010), uma melhor infraestrutura faz com que as empresas tenham uma melhor gestão de custos, sendo possível haver uma diminuição de preços relativos na produção local, além de ganhos de produtividade que geram ganhos positivos nas exportações e importações. Além disso, consumidores são beneficiados por causa de uma redução dos custos das mercadorias e consequentemente uma queda dos preços internos, o que amplia seu poder de compra além de aumentar a disponibilidade de bens, possibilitando o consumo e gerando ganhos no bem-estar do indivíduo.

O coeficiente estimado para a variável que mede o impacto da infraestrutura geral do país, apesar de ser significativa, não mostrou favorecer o comércio. Isso pode ser pelo fato do índice de infraestrutura geral conter outras variáveis, além das de infraestrutura logística, que influenciam de forma ambígua o comércio de bens manufaturados. Além disso, uma boa infraestrutura geral beneficia também o comércio interno, o que poderia gerar um desvio de parte das exportações para o mesmo. No geral, os resultados corroboram os trabalhos de Korinek e Sourdini (2011) e Paula e Silva (2015), além de corroborar as definições da OMC sobre facilitação de comércio, de que a infraestrutura está associada diretamente ao desenvolvimento do comércio internacional.

Diante dos resultados obtidos, é importante debater formas de melhorar a infraestrutura de países emergentes, como o Brasil, com políticas públicas que aumentem o investimento nessas áreas, mediante concessões, investimentos públicos focalizados, maior fiscalização dos projetos, incentivando e viabilizando investimentos privados, a fim de recuperar os níveis e diversificação necessários de infraestrutura para aumentar a competitividade do país frente aos demais.

\section{Considerações finais}

A precariedade da infraestrutura logística no Brasil é historicamente conhecida como um dos gargalos do seu processo de crescimento econômico. Citam-se os baixos níveis relativos de investimento em infraestrutura logística, além da concentração no setor de transporte rodoviária; má

Página 199 Caderno de Ciências Sociais Aplicadas, Vitória da Conquista/BA, vol. 16, n 27, ano 16, p. 187-204, jan/jun 2019. 
condição das estradas, obras inacabadas, burocracias e outros fatores que elevam os custos de frete. As pesquisas têm ressaltado a importância da infraestrutura logística sobre a competitividade, corroborando a associação positiva dessas dimensões. Nesse sentido, o presente trabalho analisou o impacto da infraestrutura, especialmente a de transportes, sobre as exportações de bens manufaturados dos países, por meio do Modelo de Gravidade. Foram utilizados dados do comércio (exportações) e de infraestrutura (índice de infraestrutura) para o ano de 2015, para 138 países.

Os resultados corroboram que a infraestrutura logística se associa positivamente à dinâmica do comércio internacional. Os índices de infraestrutura para os três modais de transporte - rodoviário, ferroviário e aeroportuário - mostraram-se significativos e positivos, ou seja, podem elevar a exportação de bens manufaturados. Já o índice de infraestrutura geral mostra-se significativo, porém negativo, justificando-se, talvez, pela razão de um maior nível de infraestrutura geral poder facilitar o comércio interno dos países, desviando parte das exportações.

Especialmente sobre o Brasil, há peso predominante das rodovias na logística e infraestrutura do país, evidenciando a precariedade dos demais modais de transporte, como os aquaviários e ferroviários. Além do baixo nível de investimento na diversificação desses modais, o Brasil ainda enfrenta uma série de deficiências em termos da qualidade das estradas, o que implica na relativa redução dos investimentos produtivos em diversas regiões. O país possui uma média histórica relativamente mais baixa de investimento em infraestrutura, desde a perda de dinamismo de sua indústria em meados da década de 1970.

Considerando os impactos que a infraestrutura, principalmente a logística, tem sobre o comércio internacional, além do fato do país ter baixa qualidade média dessa infraestrutura, em relação aos países emergentes, reforça-se a tendência de perda de competitividade internacional. O debate sobre o futuro da infraestrutura no país é um assunto importante, especialmente em uma conjuntura com restrições ao crescimento dos investimentos públicos nos próximos anos. Torna-se necessário, assim, a discussão sobre novas políticas e formas de viabilizar investimentos em projetos de infraestrutura que venham mitigar gargalos estruturais.

Por fim, vale considerar as limitações deste estudo no que concerne, principalmente, a delimitação temporal dos dados e a dificuldade de se encontrar instrumentos adequados para discussão de endogeneidade. Contudo, a literatura apresentada serviu de âncora para os resultados empíricos discutidos.

Página 200 Caderno de Ciências Sociais Aplicadas, Vitória da Conquista/BA, vol. 16, n 27, ano 16, p. 187-204, jan/jun 2019. 


\section{Referências}

ALMEIDA, F. M.; SILVA, O. M.; BRAGA, M. J. O comércio internacional do café brasileiro: a influência dos custos de transporte. Revista de Economia e Sociologia Rural. Piracicaba, SP: v. 49, n. 2, p. 323-340, 2011. Disponível em: <http://www.scielo.br/scielo.php?script=sci_arttext\&pid=S010320032011000200003>

ANDERSON, J. E. A Theoretical foundation for the gravity equation. American Economic Review. Nashville: v. 69, n. 1, p. 106-116, 1979.

ANDERSON, J. E.; VAN WINCOOP, E. Gravity with gravitas: a solution to the border puzzle. American Economic Review. Nashville: v. 93, n. 1, p. 170-192, 2003.

ANDERSON, J.E.; VAN WINCOOP, E. Trade costs. Journal of Economic Literature. [S.I.]: v. 42, n. 3, p. $691-751,2004$.

BALDWIN, R.E.; TAGLIOLI, D. Gravity for dummie and dummies for gravity equations. Centre for Economic Policy Research Discussion Paper. Londres: n. 5850. 2006. Disponível em: <http://ssrn.com/ abstract $=945443>$.

BANCO MUNDIAL. Gross domestic product ranking table. Disponível em: <http://data.worldbank.org/data-catalog/GDP-ranking-table>.

CHINELATO, F. B.; CRUZ, D. B. F.; ZIVIANI, F. Made in Brazil: O impacto da infraestrutura da logística brasileira nas operações de comércio exterior. Revista Administração em Dialogo. São Paulo: v.13, n.3, p. 44-55, set./dez. 2011. Disponível em: < https://revistas.pucsp.br/index.php/rad/article/view/7795>.

CNT - CONFEDERAÇÃO NACIONAL DO TRANSPORTE. Boletim Estatístico. Brasília. 2016. Disponível em: <http://www.cnt.org.br/Boletim/boletim-estatistico-cnt>.

CNT - CONFEDERAÇÃO NACIONAL DO TRANSPORTE . Economia em foco. Brasília. 2016. Disponível em: <http://www.cnt.org.br/publicacoes/economia-em-foco>.

CORRÊA, C. R.; GOMES, M. F. M.; LIMA, J. E. Medidas técnicas ao comércio internacional: facilitadoras de comércio ou barreiras não tarifárias? Política Externa. São Paulo: v. 24, n. 1 e 2, 2015.

DUVAL, Y. Trade facilitation beyond the Doha Round of negotiations. Asia-Pacific Research and Training Network on Trade (ARTNeT) Working Paper. [S.I.]: n. 50, 2007. Disponível em: < https://www.unescap.org/sites/default/files/AWP\%20No.\%2050.pdf>. Acesso em janeiro de 2018.

ESTACHE, A.; GARSOUS, G. The impact of infrastructure on growth in developing countries. International Finance Corporation Economics Notes. Washington, D.C.: v.1. 2012. Disponível em: < https://www.ifc.org/ >

Página 201 Caderno de Ciências Sociais Aplicadas, Vitória da Conquista/BA, vol. 16, n 27, ano 16, p. 187-204, jan/jun 2019. 
FRISCHTAK, C. R. O investimento em infra-estrutura no Brasil: histórico recente e perspectivas. Pesquisa e Planejamento Econômico. [S.I.]: v. 38, n. 2, p.307-348. 2008. Disponível em: < http://repositorio.ipea.gov.br/bitstream/11058/5192/1/PPE_v38_n02_Investimento.pdf>.

FRISCHTAK, C. R Infraestrutura e desenvolvimento no Brasil. In: Desenvolvimento econômico: uma perspectiva brasileira / Pedro Ferreira et al. - Rio de Janeiro: Elsevier, 2013 - 2a impressão.

FMI - FUNDO MONETÁRIO INTERNACIONAL. Classificação das economias. Disponível em: $<$ http://www.imf.org>.

FÓRUM ECONÔMICO MUNDIAL. The Global Competitivenes Report. Genebra: 2015. Disponível em: $<$ http://www3.weforum.org $>$.

IPEA - Instituto de Pesquisa Econômica Aplicada. Infraestrutura econômica no Brasil: diagnósticos e perspectivas para 2025. (Organizadores: Bolívar Pêgo e Carlos Alvares da Silva Campos) /IPEA. Brasília: Ipea, 2010. v.1 (586 p.). Série Eixos Estratégicos do Desenvolvimento Brasileiro. Disponível em:

http://www.ipea.gov.br/portal/images/stories/PDFs/livros/livros/Livro_InfraestruturaSocial_vol1.p $\mathrm{df}>$.

KORINEK, J.; SOURDIN, P. To What Extent Are High-Quality Logistics Services Trade Facilitating? OECD Trade Policy Papers. Paris: n. 108. 2011. Disponível em: < https://www.researchgate.net/profile/Jane_Korinek/publication/254439210_To_What_Extent_Are_ High-Quality_Logistics_Services_Trade_Facilitating/links/54042d770cf2bba34c1c3fb6/To-WhatExtent-Are-High-Quality-Logistics-Services-Trade-Facilitating.pdf>.

LIMA, E.; NASSIF, A.; CARVALHO J. R. M. Infra-Estrutura, Diversificação das Exportações e Redução do 'Custo-Brasil': Limites e Possibilidades. Revista do BNDES. Rio de Janeiro: v.4, n. 7, p.83122, $1997 . \quad$ Disponível em: <https://www.bndes.gov.br/SiteBNDES/export/sites/default/bndes_pt/Galerias/Arquivos/conheci mento/revista/rev704.pdf>.

MACHADO, R. A. Condicionantes institucionais à execução do investimento em infraestrutura no Brasil: estudo de caso sobre a implementação da ferrovia transnordestina. IPEA, Texto para discussão. Rio de Janeiro: 2251, 2016. Disponível em: <http://repositorio.ipea.gov.br/bitstream/11058/7321/1/td_2251.pdf>.

NIELSEN, L. Classifications of Countries Based on Their Level of Development: How it is Done and How it Could be Done. IMF Working Paper. [Wasington, D.C.]. 2011. Disponível em: <https://www.imf.org/en/Publications/WP/Issues/2016/12/31/Classifications-of-CountriesBasedon-their-Level-of-Development-How-it-is-Done-and-How-it-24628>.

OMC - ORGANIZAÇÃO MUNDIAL DO COMÉRCIO. Speeding up trade: benefits and challenges of implementing the WTO Trade Facilitation Agreement. World Trade Report 2015. Genebra: 2015. Disponível em: <https://www.wto.org/english/res_e/booksp_e/world_trade_report15_e.pdf>.

Página 202 Caderno de Ciências Sociais Aplicadas, Vitória da Conquista/BA, vol. 16, n 27, ano 16, p. 187-204, jan/jun 2019. 
OMC - ORGANIZAÇÃO MUNDIAL DO COMÉRCIO. World trade statistical review 2016. Genebra: 2016. Disponível em: <https://www.wto.org/english/res_e/statis_e/wts2016_e/wts2016_e.pdf>.

PAULA, J. S.; SILVA, O. M.; ALMEIDA, F. M. Evidências empiricas de indicadores de competitividade sobre os fluxos comerciais internacionais. 2012. Anais do $40^{\circ}$ Encontro Nacional de Economia. Porto de Galinhas. Disponível em <https://www.anpec.org.br/encontro/2012/inscricao/files_I/i69f99511e2783fa272684d055d50c0522.pdf >

PAULA, J. S.; SILVA, O. M. Fatores Internos como Determinantes da Competitividade no Comércio Internacional: um Enfoque Gravitacional. Análise Econômica. Porto Alegre: v. 33, n. 64, p. 191-214, 2015. Disponível em: <http://seer.ufrgs.br/AnaliseEconomica/article/view/39299/34909>.

PORTUGAL-PEREZ, A.; WILSON, J. S. Export performance and trade facilitation reform: Hard and soft infrastructure. World Development. [S.I.]: v. 40, n. 7, p. 1295-1307, 2012. Disponível em: <http://documents.worldbank.org/curated/en/232901468322759221/pdf/WPS5261.pdf>.

PÖYHÖNEN, P. A tentative model for the volume of trade between countries. Weltwirtschaftliches Archiv. [S.I.]: p. 93-100, 1963.

SHEPHERD, B. The Gravity Model of International Trade: A User Guide. United Nations publication, 2013. Disponível em < https://www.unescap.org/sites/default/ files/full-report-gravity-model-2013.pdf>

SILVA, J. S.; TENREYRO, S. The log of gravity. The Review of Economics and statistics. [S.I.]: v. 88, n. 4, p. 641-658, 2006.

SOUZA, M. J. P.; BURNQUIST, H. L. Impactos da Facilitação de Comércio: evidências do modelo gravitacional. Revista de Economia e Sociologia Rural. Piracicaba, SP: vol. 49, n. 4, p. 909-940, 2011. Disponível em: < http://www.scielo.br/pdf/resr/v49n4/a05v49n4.pdf>.

TINBERGEN, J. Shaping the world economy; suggestions for an international economic policy. Twentieth Century Fund. Nova York, 1962.

WANKE, P. F.; HIJJAR, M. F. Exportadores brasileiros: estudo exploratório das percepções sobre a qualidade da infraestrutura logística. Produção. Santa Catarina: v. 19, n. 1, p. 143-162, 2009. Disponível em: < http://www.scielo.br/pdf/prod/v19n1/10.pdf >.

ZAKI, C. An empirical assessment of the trade facilitation initiative: econometric evidence and global economic effects. World Trade Review. [S.I.]: v. 13, n. 1, p. 103-130, 2014.

Página 203 Caderno de Ciências Sociais Aplicadas, Vitória da Conquista/BA, vol. 16, n 27, ano 16, p. 187-204, jan/jun 2019. 


\section{Anexo}

Anexo 1: Amostra de países, classificados em avançados e emergentes

\begin{tabular}{|c|c|c|c|c|c|}
\hline Avançados & \multicolumn{5}{|c|}{ Emergentes } \\
\hline Alemanha & Luxemburgo & Bósnia & Filipinas & Marrocos & Rússia \\
\hline Austrália & Malta & Botswana & Gabão & Maurícias & Senegal \\
\hline Áustria & Noruega & Brasil & Gâmbia & Mauritânia & Serra Leoa \\
\hline Canadá & Nova Zelândia & Brunei & Gana & México & Sérvia \\
\hline Chipre & Países Baixos & Bulgária & Geórgia & Moçambique & Sri Lanka \\
\hline Cingapura & Portugal & Burundi & Guatemala & Moldova & Suazilândia \\
\hline Coreia do Sul & Reino Unido & Butão & Honduras & Mongólia & Tailândia \\
\hline Dinamarca & República Checa & Cabo Verde & Hungria & Montenegro & Tajiquistão \\
\hline Eslováquia & Suécia & Camarões & Iémen & Namíbia & Tanzânia \\
\hline Eslovénia & Suíça & Camboja & Índia & Nepal & Trinid. e Tobago \\
\hline Espanha & Taiwan & Catar & Indonésia & Nicarágua & Tunísia \\
\hline Estados Unidos & África do Sul & Cazaquistão & Irã & Nigéria & Turquia \\
\hline Finlândia & Albânia & Chade & Jamaica & Omã & Ucrânia \\
\hline França & Arábia Saudita & Chile & Jordão & Panamá & Uganda \\
\hline Grécia & Argélia & China & Kuwait & Paquistão & Uruguai \\
\hline Hong Kong & Argentina & Colômbia & Laos & Paraguai & Venezuela \\
\hline Irlanda & Armênia & Costa do Marfim & Lesoto & Peru & Vietnã \\
\hline Islândia & Azerbaijão & Costa Rica & Líbano & Polônia & Zâmbia \\
\hline Israel & Bahrein & Croácia & Libéria & Quénia & Zimbabwe \\
\hline Itália & Bangladesh & Egito & Macedónia & Quirguistão & \\
\hline Japão & Barbados & El Salvador & Madagascar & Rep. do Congo & \\
\hline Letônia & Bélgica & Emirados Árabes & Malásia & Rep. Dominicana & \\
\hline Lituânia & Benin & Equador & Malawi & Romênia & \\
\hline & Bolívia & Etiópia & Mali & Ruanda & \\
\hline
\end{tabular}

Fonte: Elaboração própria a partir de Fundo Monetário Internacional (2018). 